\title{
Disparities in radiation therapy delivery: current evidence and future directions in head and neck cancer
}

\author{
Henry S. Park and Roy H. Decker ${ }^{*}$
}

\begin{abstract}
Background: Though treatments for head and neck cancer have improved in recent years, significant variation persists in the delivery of surgery, radiation therapy, and systemic therapy to patients throughout the United States.

Body: In this review, we explore the current evidence regarding radiation therapy utilization inequities across the spectra of race, socioeconomic status, and age. We also discuss hypothesized mechanisms for how non-clinical factors may influence shared clinical decisions between patients and providers. Finally, we suggest future directions for research in treatment disparities.

Conclusions: Radiation therapy continues to be delivered inequitably among certain subpopulations with head and neck cancer and other cancers. More research into the drivers of these disparities and interventions designed to address them are necessary.
\end{abstract}

Keywords: Disparities, Inequity, Race, Age, Insurance, Socioeconomic, Delivery, Radiation therapy, Radiotherapy, Head and neck cancer

\section{Background}

The multidisciplinary management of head and neck cancer (HNC) has advanced rapidly in recent years. Sophisticated conformal radiation therapy techniques like intensity-modulated radiation therapy and proton beam radiation therapy, surgical approaches like transoral robotic surgery, and targeted biologic agents like cetuximab have been increasingly utilized in combination with each other to maximize tumor control while minimizing toxicities. In the setting of the rising prevalence of HPVassociated $\mathrm{HNC}$, much research is devoted to optimizing management strategies for every patient subgroup.

However, not all patients may have equal access to such advancements in cancer therapy, specifically radiation therapy. In this review, we explore the current evidence demonstrating radiation therapy utilization inequities across the spectra of race, socioeconomic status, and age. We first focus on HNC before expanding to evidence from other more common malignancies in

\footnotetext{
* Correspondence: roy.decker@yale.edu

Department of Therapeutic Radiology, Yale University School of Medicine, 15 York St, New Haven, CT 06519, USA
}

(c) 2016 The Author(s). Open Access This article is distributed under the terms of the Creative Commons Attribution 4.0 International License (http://creativecommons.org/licenses/by/4.0/), which permits unrestricted use, distribution, and reproduction in any medium, provided you give appropriate credit to the original author(s) and the source, provide a link to the Creative Commons license, and indicate if changes were made. The Creative Commons Public Domain Dedication waiver (http://creativecommons.org/publicdomain/zero/1.0/) applies to the data made available in this article, unless otherwise stated. 
a sensitivity analysis in which other-cause mortality was used as a proxy for comorbidity in multivariable logistic regression, the results did not change significantly. Second, Subramanian et al. also examined the effect of race on treatment receipt among Medicaid patients in California and Georgia with HNC [2]. After adjustment for demographics, stage at diagnosis, and tumor site, black race was not associated with differences in radiotherapy utilization, though it was associated with a lower likelihood of receiving surgery.

Medicaid insurance and lack of insurance have also been associated with disparities in treatment delivery in HNC. Inverso et al. reported that after adjustment for patient demographic data, socioeconomic factors, and tumor characteristics, uninsured patients with nonmetastatic HNC in the SEER database were more likely to not receive definitive treatment than those with any type of insurance (adjusted odds ratio 1.64, 95 \% CI 1.37-1.96) [3]. Sensitivity analyses further categorizing insurance status found that patients with no insurance or Medicaid insurance were more likely to not receive definitive treatment than those with private insurance.

Appropriate receipt vs. inappropriate omission of radiation therapy is not the only factor affecting optimal treatment delivery. Prolonged time from cancer diagnosis to treatment initiation may have an impact on tumor control and mortality [4-6]. Murphy et al. noted significant variation in time to treatment initiation by race, Hispanic ethnicity, insurance status, zip-code-level income, zip-code-level education, and age among patients with HNC in the NCDB [6].

Another source of disparities in high-quality radiation therapy delivery may be access to advanced techniques like intensity-modulated radiation therapy or proton beam radiation therapy. Both modalities have been associated with significant improvements in toxicities and quality-of-life [7-9], with one retrospective study even suggesting a cancer-specific survival benefit to intensitymodulated radiation therapy over 3D-conformal radiation therapy [10]. Using the SEER-Medicare linked database, Sher et al. found that patients living in a census tract with higher median income were significantly more likely to be treated with intensity-modulated radiation therapy [11]. No difference in intensity-modulated radiation therapy utilization by race, sex, or age was noted in any of the three published SEER-Medicare studies on this subject [10-12]. The value of proton beam radiation therapy for $\mathrm{HNC}$ is currently under active investigation. Though there are no publications available regarding disparities in proton beam radiation therapy utilization in HNC to our knowledge, this is potentially a promising field of study in the future.

An increasing amount of data supports the hypothesis that radiation therapy by high-volume providers is associated with improved outcomes in $\operatorname{HNC}[13,14]$ and multiple non-HNC malignancies like lung, cervical, and prostate cancers [15-18]. In HNC, two recent large national database analyses have noted disparities in access to high-volume providers, which may serve as another proxy for access to high-quality cancer care. First, Boero et al. found that in the SEERMedicare linked database, white patients receiving 3Dconformal radiation therapy and intensity-modulated radiation therapy for $\mathrm{HNC}$ were more significantly likely to be treated by high-volume radiation oncologists than non-white patients [13]. Second, Wuthrick et al. reported that patients with private insurance were more likely to receive HNC treatment at highaccruing facilities into Radiation Therapy Oncology Group trials than those without private insurance [14].

Table 1 summarizes the primary themes of the disparities observed in HNC.

\section{Evidence of radiation therapy delivery disparities in non- HNC malignancies}

It should be noted that racial, socioeconomic, and age disparities in radiation therapy delivery are well-documented in non-HNC cancers, such as prostate cancer [19]. Based on SEER data, African-American patients were less likely to receive curative-intent therapy (adjusted odds ratio 0.82, $95 \%$ confidence interval $0.79-0.86$ ), especially among patients with NCCN high-risk disease (adjusted odds ratio $0.60,95 \%$ confidence interval 0.56-0.64) [20]. Filipino men were also less likely to receive definitive treatment in localized prostate cancer in a SEER study of Asian-Americans [21]. Among patients receiving definitive therapy, AfricanAmerican men are more likely to receive radiation therapy but less likely to undergo surgery [20,22].

In addition, Bledsoe et al. examined the effect of insurance status on treatment selection among nonelderly patients with prostate cancer in the NCDB [23]. Even after adjustment for race and other sociodemographic and clinical factors, Medicaid patients were less than half as likely to receive minimally invasive surgery and instead

Table 1 Summary of major themes associated with disparities in radiation therapy delivery

\begin{tabular}{|c|c|}
\hline Disparity Theme & $\begin{array}{l}\text { Evidence for Disparities in Head \& } \\
\text { Neck Cancer }\end{array}$ \\
\hline $\begin{array}{l}\text { 1) Underutilization of Definitive } \\
\text { Radiation Therapy and/or Surgery }\end{array}$ & Race $[1,2]$; Insurance [3] \\
\hline $\begin{array}{l}\text { 2) Delayed Time from Diagnosis } \\
\text { to Radiation Therapy Initiation }\end{array}$ & $\begin{array}{l}\text { Race, Ethnicity, Insurance, Age, } \\
\text { Income, Education [6] }\end{array}$ \\
\hline $\begin{array}{l}\text { 3) Underutilization of Advanced } \\
\text { Radiation Therapy Techniques } \\
\text { (i.e. Intensity-Modulated Radiation } \\
\text { Therapy) }\end{array}$ & Income [11] \\
\hline $\begin{array}{l}\text { 4) Limited Access to High-Volume } \\
\text { Radiation Therapy Providers }\end{array}$ & Race [13]; Insurance [14] \\
\hline
\end{tabular}


were more than twice as likely to receive external beam radiation therapy compared to patients with private insurance. There were no differences in minimally invasive surgery and external beam radiation therapy utilization rates between patients with Medicaid insurance compared to no insurance at all. For prostate cancer patients who do receive radiation therapy in the National Cancer Data Base (NCDB) database, black and Hispanic patients were found to be significantly less likely to receive proton beam radiation therapy than white patients [24].

There is also evidence of disparities in treatment delivery beyond external beam radiation therapy in HNC and prostate cancer. Grant et al. examined patients in the SEER database to determine the association between insurance status and brachytherapy receipt [25]. The study showed that patients who received radiation therapy definitively for prostate and cervical cancer or postoperatively for breast cancer were less likely to receive brachytherapy if they had Medicaid coverage (odds ratio $0.57,95 \%$ CI $0.53-0.61$ ) or no insurance coverage (odds ratio $0.50,95 \%$ CI $0.45-0.56$ ) compared to those with non-Medicaid insurance. A SEER study of 3,851 black patients and 44,010 white patients with rectal cancer showed that black patients were significantly more likely to receive no radiation therapy for stage II to III disease (adjusted odds ratio 1.30, $95 \%$ confidence interval 1.151.47) [26]. Older patients were less likely to receive the standard-of-care combination of radiation therapy with fluorouracil-based chemotherapy among 1,807 Medicare beneficiaries with stage II to III rectal cancer in the SEER-Medicare database [27]. Similar trends were noted in stage I to II breast cancer, as older women were less likely to receive optimal local treatment with radiation therapy and surgery $[28,29]$.

\section{Potential mechanisms}

We have now shown that sociodemographic factors may play a significant role in contributing to gaps in radiation therapy delivery. Disparities in radiation therapy delivery may be at least partially related to differences in referral patterns to radiation oncologists. The lung cancer literature has studied this feature most extensively. Goulart et al. analyzed data from 28,977 patients with stage III and IV non-small cell lung cancer diagnosed in 20002005 from the SEER-Medicare database linked with the American Medical Association Masterfile database [30]. On multivariable analysis, older age, black race, and female sex were associated with a lower likelihood of seeing all cancer specialists (medical oncologists, radiation oncologists, and thoracic or general surgeons). Seeing all three types of cancer specialists was predictive of a significantly higher likelihood of receiving National Comprehensive Cancer Network (NCCN) guideline-based therapies. Although these numbers were not explicitly reported in the manuscript, our calculations reveal that the likelihood of receiving guideline-based therapies for patients with vs. without radiation oncologist referral was $64.1 \%$ vs. $20.1 \%$ for stage IIIA disease and $56.3 \%$ vs. $6.3 \%$ for stage IIIB disease.

Australian data by Vinod et al. also show disparities in radiation oncologist referrals [31]. Based on questionnaire data from diagnosing and treating clinicians for 1,812 lung cancer patients from New South Wales, the authors found significant underutilization of curativeintent radiation therapy to the primary site $(20 \%$ actual vs. $50 \%$ optimal), especially in patients with limitedstage small cell lung cancer ( $46 \%$ actual vs. $94 \%$ optimal). Older patients were again less likely to be referred to radiation oncologists, as were patients who lived in areas that were not highly accessible by distance to major service centers based on the Accessibility and Remoteness Index for Australia. Patient sex did not impact referral patterns, while race and income level were not analyzed in this study.

Other reasons for disparities in radiation therapy delivery can be considered within a framework involving three broad categories: poverty, culture, and social injustice [32]. Barriers related to poverty and low socioeconomic status include the lack of a primary care physician, who would conduct screening and diagnostic follow-up; limited access to healthcare based on geographical inconveniences; competing survival priorities such as obtaining food, shelter, and safety; medical comorbidities; lack of adequate health insurance; lack of information and knowledge; and risk-promoting lifestyles, like poor nutrition and physical inactivity [33, 34].

Cultural factors, which reflect a set of learned and shared beliefs, values, traditions, world views, communication styles, and behavior common to a particular social group, can also play a large role in racial disparities in treatment delivery. Factors like spirituality, perceived susceptibility to cancer, cultural beliefs about cancer, and medical mistrust can be major barriers for certain cultural groups [33]. For instance, black women often consider themselves at lower risk for developing breast cancer than white women, even among those with a family history of breast cancer, which may translate into low perceived need for mammography or delays in seeking treatment for a breast abnormality [35]. There may also be a more fatalistic attitude regarding breast cancer treatment, less confidence in Western medicine, more confidence that spirituality and divine intervention are more effective in promoting cure, and a cultural norm against discussing breast cancer among certain cultural groups [36-39]. Traditional practices like Ayurvedic and Traditional Chinese medicine or Mexican herbal mixtures may or may not have beneficial or harmful effects on cancer treatment, especially regarding interactions 
with radiation therapy or chemotherapy. However, disclosure of this information by patients may be hindered by fear of receiving judgmental or dismissive comments from oncology providers, thereby excluding the potential of communication about these issues [34]. Patientprovider communication is also critical when addressing medical truth-telling at the end-of-life in certain family and community-centered societies, where practices of nondisclosure often persist due to cancer-related social stigma [34].

Social injustice, including factors like racial prejudice and discrimination, may also factor into racial disparities, but this relationship does not appear to have been as well studied as socioeconomic status or culture [32]. Provider perceptions of racial minority patients may affect quality of care, as physicians rated black patients with coronary artery disease as less educated and less likely to comply with treatment, even after adjusting for socioeconomic status [40]. In addition, black women were more likely to report a lack of physician recommendation as a reason for not undergoing mammography [41]. While it is certainly debatable whether or not these findings due to racial prejudice or other factors, perceived racial discrimination by patients may also play a role in differences in cancer incidence as well as treatment and satisfaction with care [42]. For instance, black women younger than 50 years who reported higher levels of racial discrimination in "everyday" experiences were at greater risk of subsequently developing breast cancer, since perceived racism could act as a chronic stressor that alters immune functioning and/or endogenous hormone levels [43].

\section{Conclusions}

Radiation therapy continues to be delivered inequitably among certain subpopulations with head and neck cancer and other cancers. Ultimately, it appears that the key to future research on treatment disparities in cancer lies upon disentangling apparent effects of race, poverty, age, education, and discrimination. It is also important to improve the measurement accuracy of specific indicators of socioeconomic status beyond broad measures of household income in a given zip code or census tract. In order to close these gaps, we must evaluate various communication practices in the way treatments are decided and patient autonomy is upheld.

We must also venture well beyond medical care itself. Patient education regarding high-risk behavior like smoking, obesity, and environmental hazards; programs facilitating travel to healthcare organizations; legislative action to improve access to healthcare; and general improvements in housing, schooling, and neighborhood safety must all be addressed before disparities caused by these factors can be minimized. However, it is still unclear if and how interventions addressing these areas could make a measurable difference.

With improving awareness of the complexity of this problem, there will hopefully be a growth in research infrastructure capturing this necessary data. More sophisticated analyses that account for these covariates will help clarify the most critical determinants of these disparities and to create and evaluate interventions on individual, locoregional, national, and international levels to address and eliminate them.

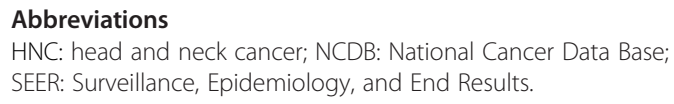

\section{Authors' contributions}

HP drafted the manuscript. All authors (HP and RD) read and approved the final manuscript.

\section{Competing interests}

Neither Dr. Park nor Dr. Decker have any competing interests to report.

\section{Ethics approval}

Not applicable.

\section{Disclosures}

Dr. Park has received honoraria and travel expenses from Varian Medical Systems, Inc. (past). Dr. Decker receives research funding from $21^{\text {st }}$ Century Oncology (ongoing) and Merck \& Co., Inc. (ongoing), and has consulted for AMAG Pharmaceuticals, Inc. (past) and Leidos Biomedical Research, Inc. (ongoing). These funding sources had no involvement in the design, analysis, or preparation of the manuscript. The authors have no relevant competing interests to disclose.

Received: 23 March 2016 Accepted: 17 May 2016

Published online: 13 June 2016

\section{References}

1. Mahal BA, Inverso G, Aizer AA, et al. Impact of African-American race on presentation, treatment, and survival of head and neck cancer. Oral Oncol. 2014:50:1177-81.

2. Subramanian $\mathrm{S}$, Chen A. Treatment patterns and survival among lowincome medicaid patients with head and neck cancer. JAMA Otolaryngol Head Neck Surg. 2013;139:489-95.

3. Inverso G, Mahal BA, Aizer AA, et al. Health Insurance Affects Head and Neck Cancer Treatment Patterns and Outcomes. J Oral Maxillofac Surg. 2016; Epub ahead of print. doi:10.1016/j.joms.2015.12.023.

4. Neal RD, Tharmanathan $P$, France $B$, et al. Is increased time to diagnosis and treatment in symptomatic cancer associated with poorer outcomes? Systematic review. Br J Cancer. 2015;112 Suppl 1:S92-107.

5. McLaughlin JM, Anderson RT, Ferketich AK, et al. Effect on survival of longer intervals between confirmed diagnosis and treatment initiation among lowincome women with breast cancer. J Clin Oncol. 2012;30:4493-500.

6. Murphy CT, Galloway TJ, Handorf EA, et al. Survival Impact of Increasing Time to Treatment Initiation for Patients With Head and Neck Cancer in the United States. J Clin Oncol. 2016;34:169-78.

7. Kam MK, Leung SF, Zee B, et al. Prospective randomized study of intensitymodulated radiotherapy on salivary gland function in early-stage nasopharyngeal carcinoma patients. J Clin Oncol. 2007;25:4873-9.

8. Nutting CM, Morden JP, Harrington KJ, et al. Parotid-sparing intensity modulated versus conventional radiotherapy in head and neck cancer (PARSPORT): a phase 3 multicentre randomised controlled trial. Lancet Oncol. 2011;12:127-36

9. Romesser PB, Cahlon O, Scher E, et al. Proton beam radiation therapy results in significantly reduced toxicity compared with intensity-modulated radiation therapy for head and neck tumors that require ipsilateral radiation. Radiother Oncol. 2016;1 18:286-92. 
10. Beadle BM, Liao KP, Elting LS, et al. Improved survival using intensitymodulated radiation therapy in head and neck cancers: a SEER-Medicare analysis. Cancer. 2014;120:702-10.

11. Sher DJ, Neville BA, Chen AB, et al. Predictors of IMRT and conformal radiotherapy use in head and neck squamous cell carcinoma: a SEERMedicare analysis. Int J Radiat Oncol Biol Phys. 2011;81:e197-206.

12. Yu JB, Soulos PR, Sharma R, et al. Patterns of care and outcomes associated with intensity-modulated radiation therapy versus conventional radiation therapy for older patients with head-and-neck cancer. Int J Radiat Oncol Biol Phys. 2012;83:e101-7.

13. Boero IJ, Paravati AJ, Xu B, et al. Importance of Radiation Oncologist Experience Among Patients With Head-and-Neck Cancer Treated With Intensity-Modulated Radiation Therapy. J Clin Oncol. 2016;34:684-90.

14. Wuthrick EJ, Zhang Q, Machtay M, et al. Institutional clinical trial accrual volume and survival of patients with head and neck cancer. J Clin Oncol. 2015;33:156-64.

15. Chen AB, D'Amico AV, Neville BA, et al. Provider case volume and outcomes following prostate brachytherapy. J Urol. 2009;181:113-8. discussion 118.

16. Chen YW, Mahal BA, Muralidhar V, et al. Association Between Treatment at a High-Volume Facility and Improved Survival for Radiation-Treated Men With High-Risk Prostate Cancer. Int J Radiat Oncol Biol Phys. 2016;94:683-90.

17. Wang EH, Rutter CE, Corso CD, et al. Patients Selected for Definitive Concurrent Chemoradiation at High-volume Facilities Achieve Improved Survival in Stage III Non-Small-Cell Lung Cancer. J Thorac Oncol. 2015;10: 937-43.

18. Lin JF, Berger JL, Krivak TC, et al. Impact of facility volume on therapy and survival for locally advanced cervical cancer. Gynecol Oncol. 2014;132:416-22.

19. McGinley KF, Tay KJ, Moul JW. Prostate cancer in men of African origin. Nat Rev Urol. 2016;13:99-107.

20. Mahal BA, Aizer AA, Ziehr DR, et al. Trends in disparate treatment of African American men with localized prostate cancer across National Comprehensive Cancer Network risk groups. Urology. 2014;84:386-92.

21. Chao GF, Krishna N, Aizer AA, et al. Asian Americans and prostate cancer: A nationwide population-based analysis. Urol Oncol. 2016;34:233.e7-233.e15.

22. Moses KA, Paciorek AT, Penson DF, et al. Impact of ethnicity on primary treatment choice and mortality in men with prostate cancer: data from CaPSURE. J Clin Oncol. 2010;28:1069-74.

23. Bledsoe TJ, Park HS, Rutter CE, et al. Minimally invasive surgery and external beam radiation therapy selection for prostate cancer varies significantly by health insurance status. Int J Radiat Oncol Biol Phys. 2015;93:e358-59.

24. Mahal BA, Chen YW, Efstathiou JA, et al. National trends and determinants of proton therapy use for prostate cancer: A National Cancer Data Base study. Cancer. 2016;122:1505-12.

25. Grant SR, Walker GV, Koshy M, et al. Impact of Insurance Status on Radiation Treatment Modality Selection Among Potential Candidates for Prostate, Breast, or Gynecologic Brachytherapy. Int J Radiat Oncol Biol Phys. 2015;93: 968-75.

26. Morris AM, Billingsley KG, Baxter NN, et al. Racial disparities in rectal cancer treatment: a population-based analysis. Arch Surg. 2004;139:151-5. discussion 156.

27. Neugut Al, Fleischauer AT, Sundararajan V, et al. Use of adjuvan chemotherapy and radiation therapy for rectal cancer among the elderly: a population-based study. J Clin Oncol. 2002:20:2643-50.

28. August DA, Rea T, Sondak VK. Age-related differences in breast cancer treatment. Ann Surg Oncol. 1994;1:45-52.

29. Ayanian JZ, Guadagnoli E. Variations in breast cancer treatment by patient and provider characteristics. Breast Cancer Res Treat. 1996;40:65-74.

30. Goulart BH, Reyes CM, Fedorenko CR, et al. Referral and treatment patterns among patients with stages III and IV non-small-cell lung cancer. J Oncol Pract. 2013;9:42-50.

31. Vinod SK, Simonella L, Goldsbury D, et al. Underutilization of radiotherapy for lung cancer in New South Wales, Australia. Cancer. 2010;116:686-94.

32. Freeman HP, Chu KC. Determinants of cancer disparities: barriers to cancer screening, diagnosis, and treatment. Surg Oncol Clin N Am. 2005;14:655-69.

33. Gerend MA, Pai M. Social determinants of Black-White disparities in breast cancer mortality: a review. Cancer Epidemiol Biomarkers Prev. 2008;17:2913-23.

34. Kagawa-Singer M, Dadia AV, Yu MC, et al. Cancer, culture, and health disparities: time to chart a new course? CA Cancer J Clin. 2010;60:12-39.

35. Lannin DR, Mathews HF, Mitchell J, et al. Influence of socioeconomic and cultural factors on racial differences in late-stage presentation of breast cancer. JAMA. 1998;279:1801-7.
36. Lannin DR, Mathews HF, Mitchell J, et al. Impacting cultural attitudes in African-American women to decrease breast cancer mortality. Am J Surg. 2002;184:418-23.

37. Phillips JM, Cohen MZ, Tarzian AJ. African American women's experiences with breast cancer screening. J Nurs Scholarsh. 2001;33:135-40.

38. Johnson KS, Elbert-Avila Kl, Tulsky JA. The influence of spiritual beliefs and practices on the treatment preferences of African Americans: a review of the literature. J Am Geriatr Soc. 2005;53:711-9.

39. George M, Margolis ML. Race and lung cancer surgery-a qualitative analysis of relevant beliefs and management preferences. Oncol Nurs Forum. 2010; 37:740-8.

40. van Ryn M, Burke J. The effect of patient race and socio-economic status on physicians' perceptions of patients. Soc Sci Med. 2000;50:813-28.

41. Vernon SW, Vogel VG, Halabi S, et al. Factors associated with perceived risk of breast cancer among women attending a screening program. Breast Cancer Res Treat. 1993;28:137-44.

42. Mandelblatt JS, Edge SB, Meropol NJ, et al. Predictors of long-term outcomes in older breast cancer survivors: perceptions versus patterns of care. J Clin Oncol. 2003;21:855-63.

43. Taylor TR, Williams CD, Makambi KH, et al. Racial discrimination and breast cancer incidence in US Black women: the Black Women's Health Study. Am Epidemiol. 2007;166:46-54

\section{Submit your next manuscript to BioMed Central and we will help you at every step:}

- We accept pre-submission inquiries

- Our selector tool helps you to find the most relevant journal

- We provide round the clock customer support

- Convenient online submission

- Thorough peer review

- Inclusion in PubMed and all major indexing services

- Maximum visibility for your research

Submit your manuscript at www.biomedcentral.com/submit
) Biomed Central 